\title{
BEHAVIOR OF WOVEN FABRIC REINFORCED EPOXY COMPOSITES UNDER BENDING AND COMPRESSIVE LOADS
}

\author{
M. Abdel Ghafaar ; A. A. Mazen \\ Design and Production Engineering Department, Faculty of Engineering, Minia \\ University, Minia, Egypt
}

\section{N. A. El-Mahallawy}

Production Engineering Department, Faculty of Engineering, Ain Shams University, Cairo, Egypt

(Received October 16, 2005 Accepted January 21, 2006)

\begin{abstract}
The mechanical behavior of epoxy reinforced by three different types of woven fibers was studied under compressive and bending loads. The reinforcements used were: woven glass fibers (volume fractions: 9.2\%, 18.4\%, 27.6\%, and 36.8\%), woven carbon fibers, and woven hybrid (carbon/glass) fibers at 36.8 vol. $\%$, each. The composites were manufactured using the hand lay-up technique.

Pure (unreinforced) epoxy specimens were tested as a reference material. The fracture behavior of the investigated specimens was studied both macroscopically, and using scanning electron microscopy (SEM). It was found that under compressive loads, elastic deformation is nonlinear for pure epoxy as well as epoxy reinforced by low volume fractions of glass woven fibers. At high volume fractions of glass fibers, carbon fibers, or hybrid ones, this non linearity diminished significantly.

The modulus of elasticity of epoxy-reinforced by glass fibers (GF) continued to increase as a function of fiber volume fraction. At 9.2 vol.\% the modulus of elasticity showed an increase of $65 \%$ compared to pure epoxy, while at 36.8 vol. $\%$ GF the improvement reached $117 \%$. At the same volume fraction of $36.8 \%$ hybrid, and carbon reinforcements the improvements were $160 \%$, and $178 \%$, respectively.

Similar trend of improvements were observed for the other mechanical properties under compressive loads.

Under bending loads, both the flexure modulus, and flexure strength showed significant improvement as a function of glass fiber volume fraction. At the same reinforcement volume fraction, carbon fiber composites gave the highest mechanical properties, followed by hybrid composites, while glass fiber composites showed lowest improvement (about 348\% improvement in flexure strength compared to pure epoxy).

Fiber pull-out and debonding are the main fracture mechanisms for glass fiber reinforced epoxy, while interlaminar shearing is the main mechanism for carbon fiber composites. Hybrid $(C / G)$ composites showed a mixed mode mechanism.

The fracture process in bending proceeded in stages from the tension side inwards towards the compression side. Each stage is associated with a load drop and audible sound waves.
\end{abstract}

KEYWORD : Epoxy - hand lay-up - woven fabrics - compressive - Bending mechanical properties. 


\section{INTRODUCTION}

Since the development of polymeric matrix reinforced composites about half a century ago, this field has witnessed fast and dynamic developments in all of its aspects. New types of fibers and fiber fabrication techniques have been developed, e.g. aramid fibers, carbon fibers, development of sol-gel techniques for glass and ceramic fibers manufacturing in the 1970's [1 -4].

These fabrication developments allowed materials engineers to look for polymeric matrix composites as a potential alternative to substitute for conventional materials in many applications. Polymeric matrix composites are now being used in almost all engineering applications, e.g. automotive industries, aeroplanes, military fighter aircrafts, marine applications, construction applications sports applications, etc.[5-8].

The use of polymeric matrix composites in so many applications involved subjecting these materials to different types of loading. Thus, the need for research dealing with characterization of the mechanical behavior of these materials continues to be strong.

The use of woven fibers was introduced to solve the problem of the high anisotropic behavior of unidirectional composites. Woven fabric reinforced composites are orthotropic and they have similar properties in the length and width directions, i.e., the warp and fill directions $[9,10]$.

Several investigators studied the behavior of polymeric matrix composites reinforced by woven fabrics. Hayat and Sulliman [11] studied composites made with different phenolic systems with different woven roving reinforcements prepared by hand lay-up technique. Their results showed that a reasonable degree of reproducibility can be achieved in phenolic laminates. However, the finishes on commercially available glass woven rovings have poor compatibility with phenolic resins which negatively affects the mechanical and structural strengths.

Unidirectional hybrid composites manufactured with polyester matrix reinforced by carbon / glass woven fabrics were studied in ref. [8]. The carbon volume fraction in the warp direction was varied from zero to 90 vol.\%. The stress-strain curves obtained were linear till complete fracture. Both the modulus of elasticity and tensile strength increased linearly with the carbon content in the warp direction. Carbon fibers were found to control the failure process. This was attributed to their high stiffness and low strain to failure.

The effect of stacked fabric layers were investigated by different authors [12 - 14]. Jekabsons and Bystrom [12] investigated the effects of stacked fabric layers on the stiffness of woven composites. They found that multi-layer composites showed more linear stress-strain curves, and also had a higher initial E-modulus.

The goal of the present work is to present an experimental study dealing with epoxy composites reinforced with three different woven reinforcements, i.e., glass, carbon and hybrid (glass/carbon) woven fabrics. The composites were manufactured using the hand lay-up technique. The behavior of the composites under compressive and 3-point bending was investigated. Bending involves subjecting the component to tensile as well as compressive stresses. Behavior of the present composite materials under tensile stresses was discussed earlier in a separate paper [13]. The fracture process was investigated both macroscopically and using a scanning electron microscope (SEM). 


\section{EXPERIMENTAL PROCEDURES}

\subsection{Materials}

General purpose epoxy (MIL-A-8623) was used as a matrix. A polyamide resin was used as a hardener as per supplier's instruction. Table 1 gives the characteristics of the resulting matrix blend.

Table 1. Characteristics of the matrix blend ${ }^{(1)}$.

\begin{tabular}{|l|c|c|c|}
\hline & Part A & Part B & Blend \\
\hline Resin system & Epoxy & Polyamide & Epoxy \\
\hline Color & Off white & Tan & Tan \\
\hline Viscosity $\left[\mathrm{C}_{\mathrm{p}}-(\mathrm{MPa} . \mathrm{s})\right]$ & 25000 & 60000 & 62000 \\
\hline Density $\left(\mathrm{kg} / \mathrm{cm}^{3}\right)$ & 0.00116 & 0.00127 & 0.00121 \\
\hline Blending ratio by volume & 1 & 1 & 1 \\
\hline Weight per gallon (pound) & 10.4 & 11.4 & 10.9 \\
\hline
\end{tabular}

(1) Provided by supplier.

Two types of woven fibers were used to produce three different types of reinforcements, e.g. woven glass fibers, woven carbon fibers, and hybrid reinforcements made by alternating layers of glass and carbon woven fabrics. The characteristics of the two types of fibers are given in Table 2, below.

Table 2. Characteristics of the woven fabric reinforcements.

\begin{tabular}{|l|c|c|}
\hline & E-glass woven fabrics & Carbon woven fabrics \\
\hline Color & White & Black \\
\hline Density $(\mathrm{g} / \mathrm{cc})$ & 2.54 & 1.75 \\
\hline Tensile strength $\left(\mathrm{N} / \mathrm{mm}^{2}\right)$ & 3450 & 3530 \\
\hline Sp. Strength $\left(\mathrm{N} / \mathrm{mm}^{2}\right)$ & 1350 & 2017.14 \\
\hline Modulus of elasticity $(\mathrm{GPa})$ & 72 & 230 \\
\hline Weight $\left(\mathrm{gm} / \mathrm{m}^{2}\right)$ & 320 & 200 \\
\hline Sp. Modulus $(\mathrm{GPa}) /(\mathrm{gm} / \mathrm{cc})$ & 28.1 & 131.43 \\
\hline
\end{tabular}

\subsection{Specimens Fabrication}

The hand lay-up technique was used for specimen fabrication. A special wooden mould $(300 \times 75 \mathrm{~mm})$ with well finished smooth surfaces was prepared. Pre calculated volume of fibers were laid in the mould. Each ply was carefully covered with the resin till saturation. Excess resin and air bubbles were squeezed out using a roller before placing the next ply. For the hybrid composites, carbon and glass fabrics were placed alternately. The mould was covered using a cellophane sheet, and a $15 \mathrm{~kg}$ platen was placed on top.

The materials were cured at a temperature of $70^{\circ} \mathrm{C}\left(158^{\circ} \mathrm{F}\right)$ for 2.50 hours as per supplier's instructions.

Compression, and bending specimens were cut from the cured materials. Loading tabsfabricated separately-were bonded to the ends of the compressive specimens.

Figures 1 and 2 show sketches of the different specimen geometries. 


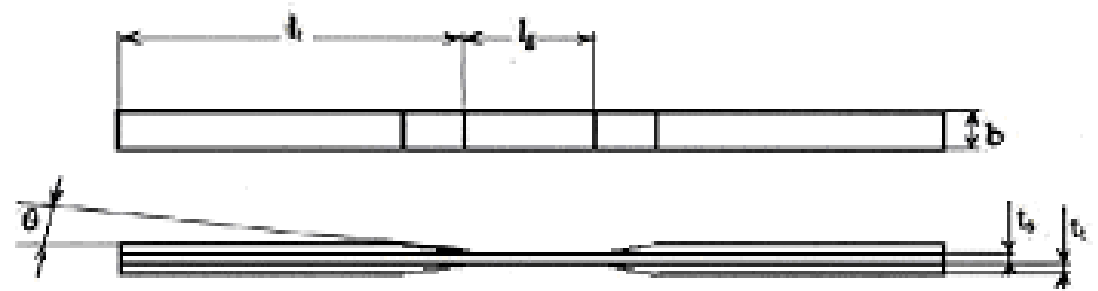

Dimensions of the compression test specimen

\begin{tabular}{|c|c|c|c|}
\hline Type of continuous fiber reinforcement & Carbon/epoxy & Ifybrid & Glass/epoxy \\
\hline Gauge length $I_{2}(\mathrm{~mm})$ & 12.7 & 12.7 & 12.7 \\
\hline Tab length $l_{1}(\mathrm{~mm})$ & 63.50 & 63.50 & โ28 \\
\hline Specimen width b(mnt) & 6.35 & 6.35 & 6.35 \\
\hline Tapering angle $\theta$ (degree) & $15^{0}$ & $15^{0}$ & $15^{0}$ \\
\hline Tab thickness $t_{t}(\mathrm{~mm})$ & 2 & 2 & 2 \\
\hline Specimen thickness $t_{s}(\mathrm{~mm})$ & 2.54 & 2.75 & 3 \\
\hline
\end{tabular}

Fig. 1: Geometry of the compression test specimen according to ASTM D3410-75 (1987)

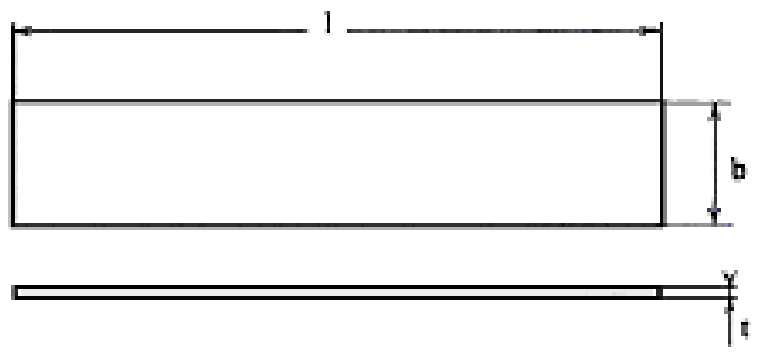

Dimensions of the bending test speeimen

\begin{tabular}{|c|c|c|c|}
\hline Type of continuous flber reinforcement & Carbon/epaxy & Hybrid & Glass/cpoxy \\
\hline Gauge lewsth te (mon) & 50 & 50 & 50 \\
\hline Specimen length I(min) & 80 & 80 & 80 \\
\hline Specimen width b(mm) & 25 & 25 & 25 \\
\hline Specimen thickness $t(\mathrm{~mm})$ & 2.54 & 2.75 & 3 \\
\hline
\end{tabular}

Fig. 2: Geometry of the bending test specimen according to ASTM D790-82 (2002)

\subsection{Fiber Volume Fraction Determination}

$10 \times 10 \mathrm{~mm}$ specimens of all fabricated composite specimens were cut. The matrix of each specimen was dissolved in a $30 \%$ concentration $\mathrm{H}_{2} \mathrm{SO}_{4}$ acid solution. The fibers were then extracted, dried-up, and weighed. Using simple calculations, and knowing the density of fibers, its dry weight, and the volume of specimen before dissolution, it was possible to calculate the fiber volume fraction for each type of composite. These were found to be: for glass fiber reinforced epoxy: 9.2 vol. $\%, 18.4$ vol. $\%, 27.6$ vol. $\%$, 
and 36.8 vol.\%; for carbon fiber-reinforced epoxy, and the hybrid fiber reinforced one, the fiber volume fraction was found to be $36.8 \%$, each.

\subsection{Mechanical Testing}

Compression tests were conducted in a universal testing machine. The specimen geometry and dimensions were made according to ASTM D 3410-75 (1987), Fig. 1. The cross-head speed used for all tests was $2 \mathrm{~mm} / \mathrm{min}$. Tests were carried out monotonically to fracture without interruption. The wedge shaped grips had sharp serrations that prevented slip during the tests. The grips were marked in the middle before testing to ensure repetition of positioning of the specimen and to avoid eccentricity which may result-in complex state of stress.

Wang [15], showed that if the compressive load applied to the specimen is less than the critical load required for buckling, the specimen remains straight and undergoes only axial compression. If the specimen is displaced from this equilibrium form or if the load exceeded the Euler's load, the specimen will assume a bent form.

During compressive testing of the present work, the above mentioned precautions were taken to ensure axial loading. Besides, the specimen shape was monitored closely during loading to ensure the straightness of each specimen.

Special loading attachment was designed and constructed to perform the 3-point bending tests on a universal testing machine. The attachment had three circular heads. Two heads were made $50 \mathrm{~mm}$ apart to support the gauge length of the specimen, leaving $15 \mathrm{~mm}$ on each side as free length. Thus, the total length of the specimen is $80 \mathrm{~mm}$. The third head was attached to the loading grips of the universal testing machine, Fig. 2a. Circular heads ensure line contact between them and the flat specimens. Bend testing specimens were fabricated according to ASTM D790-82 (2002), see Fig. 2b.

Due to the slight nonlinearity exhibited by the stress-strain curves of the composite specimens during compressive loading, the elastic moduli for these specimens were measured using the secant modulus taken at a stress of $20 \mathrm{MPa}$.

The flexure strength, $\sigma_{b}$, and flexure modulus, $E_{b}$, were calculated from the load deflection curves using the following equations :

$$
\begin{array}{ll}
\sigma_{\mathrm{b}} & =3 \mathrm{P}_{\max } \mathrm{L} / 2 \mathrm{bh}^{2} \\
\mathrm{E}_{\mathrm{b}} & =3 \mathrm{PL}^{3} / 4 \mathrm{~b} \delta \mathrm{h}^{3}
\end{array}
$$

Where:

$\begin{array}{llll}\text { P } & \text { machine load, } & \text { L } & \text { gauge (span) length, } \\ \text { b } & \text { specimen width, } & \text { h } & \text { specimen thickness } \\ \delta & \text { vertical displacement at onset of fracture. }\end{array}$

\section{RESULTS AND DISCUSSION}

\subsection{Behavior Under Compressive Loads}

Figure $\mathbf{3 a}$ shows the compressive stress-strain curves for pure epoxy, and epoxy reinforced by different volume fractions of woven glass fibers. Figure $\mathbf{3} \mathbf{b}$ shows the compressive stress-strain curves of epoxy reinforced by $36.8 \mathrm{vol} \%$ of the three different woven fibers, i.e., glass, carbon, and hybrid (glass/carbon) woven fabric. 
It is clear that compressive deformation proceeded in elastic fashion till fracture. However, the elastic deformation is nonlinear. This nonlinearity is quite pronounced in the case of pure epoxy and epoxy reinforced by 9.2 vol.\% GF, 18.4 vol.\% GF, and 27.6 vol.\% GF. It diminished significantly for epoxy-36.8 vol.\% GF, and the elastic curve shows clear linearity for the cases of epoxy-36.8 vol.\% CF, and 36.8 vol.\% hybrid fibers.

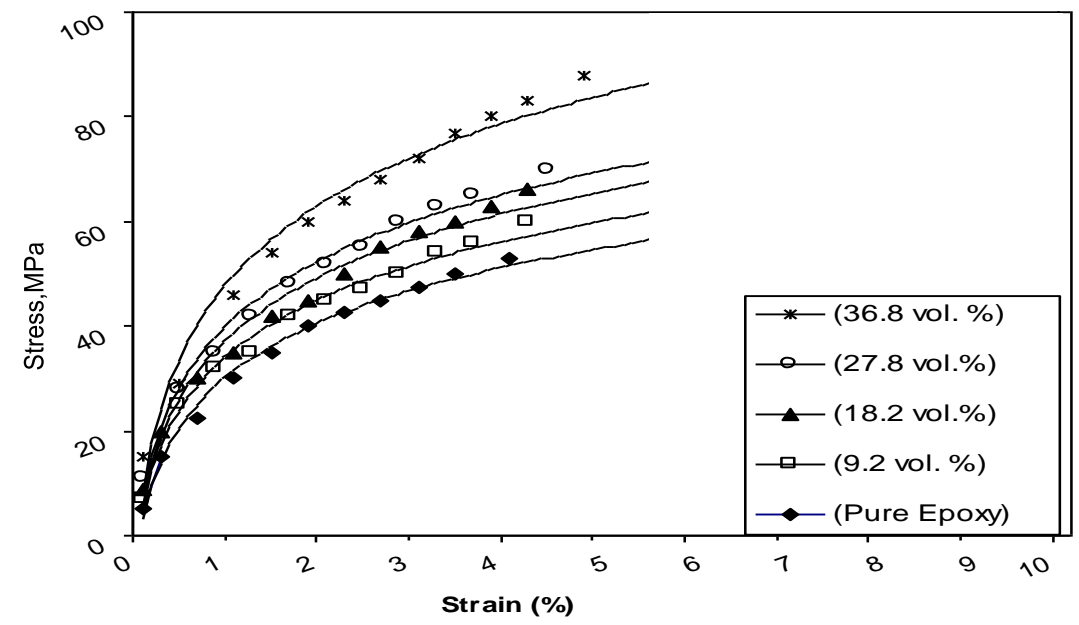

Fig. 3a: Stress-Strain Curves under Compression for Pure Epoxy \& Glass Fibers Composites.

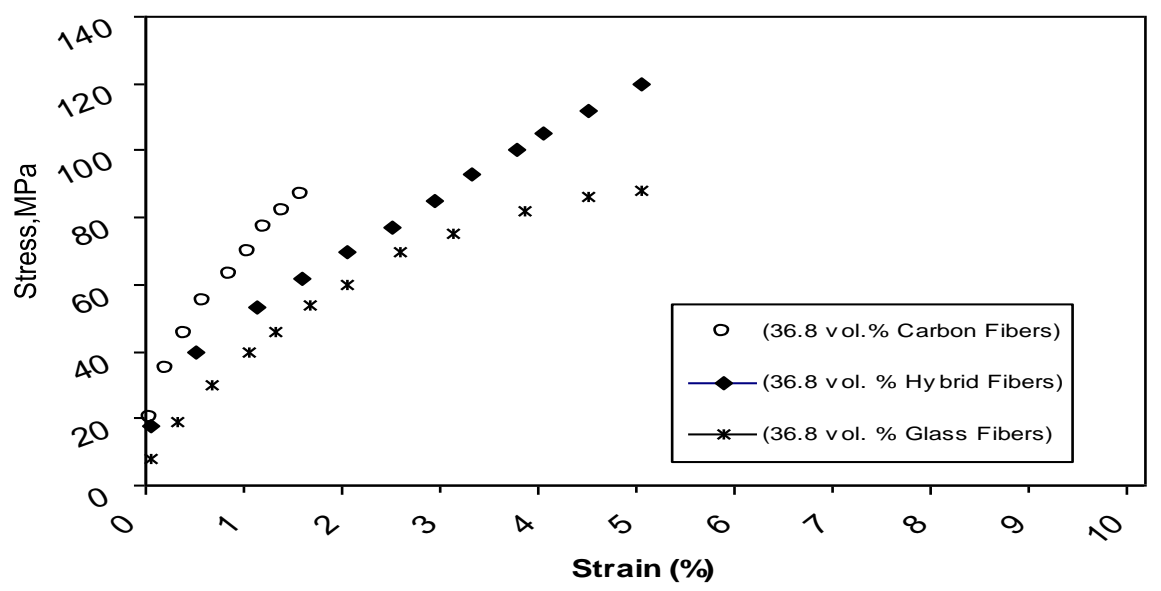

Fig. 3b: Stress-Strain Curves under Compression for different Composites.

This shows that under compressive loads, the material exhibits two different regimes depending on fiber volume fraction. For pure epoxy and epoxy reinforced with low volume fractions of reinforcements, the behavior is matrix-controlled. For epoxy reinforced by high volume fraction of woven fibers, i.e., 36.8 vol.\% GF, CF, or hybrid 
fibers, the deformation is reinforcement-controlled. Such result is in agreement with the SEM fractographic results as will be discussed shortly.

Tables 3a, b show summary of the mechanical properties of the investigated composites, i.e., the strain at fracture, the compressive stress, and the modulus of elasticity in compression. Figures $\mathbf{4 a}, \mathbf{b}$ and $\mathbf{c}$ show the variations of elastic modulus, fracture stress, and strain at fracture under compressive loads, as a function of glass fiber volume fraction, and the type of reinforcing fibers. It is clear that all mechanical parameters increase as the reinforcement volume fraction increases.

Table 3a: Summary of Compressive Properties for GFRE.

\begin{tabular}{|c|c|c|c|}
\hline $\begin{array}{c}\text { Volume } \\
\text { fractions of } \\
\text { FGRE }\end{array}$ & $\begin{array}{c}\text { Strain at } \\
\text { fracture \% }\end{array}$ & $\begin{array}{c}\text { Fracture } \\
\text { compression } \\
\text { stress (MPa) }\end{array}$ & $\begin{array}{c}\text { Longitudinal } \\
\text { modulus of } \\
\text { elasticity E(Gpa) }\end{array}$ \\
\hline 0 & 3.625 & 51 & 3.45 \\
\hline $9.2 \%$ & 3.81 & 56.875 & 5.7 \\
\hline $18.4 \%$ & 3.9 & 57.75 & 6.3 \\
\hline $27.8 \%$ & 4.08 & 66.5 & 6.83 \\
\hline $36.8 \%$ & 4.75 & 81.725 & 7.5 \\
\hline
\end{tabular}

Table 3b: Summary of Compressive Properties for the different composites.

\begin{tabular}{|c|c|c|c|c|}
\hline $\begin{array}{c}\text { Types of } \\
\text { laminates }\end{array}$ & $\mathbf{V}_{\mathbf{f}}$ & $\begin{array}{c}\text { Strain at } \\
\text { fracture \% }\end{array}$ & $\begin{array}{c}\text { Fracture } \\
\text { compressive } \\
\text { stress (Mpa) }\end{array}$ & $\begin{array}{c}\text { Longitudinal } \\
\text { modulus of } \\
\text { elasticity E (Gpa) }\end{array}$ \\
\hline GFRE & $36.8 \%$ & 4.75 & 81.725 & 7.5 \\
\hline Hybrid & $36.8 \%$ & 4.5 & 113 & 9 \\
\hline CFRE & $36.8 \%$ & 1.375 & 84.5 & 9.6 \\
\hline
\end{tabular}

* Based on testing of 3 specimens

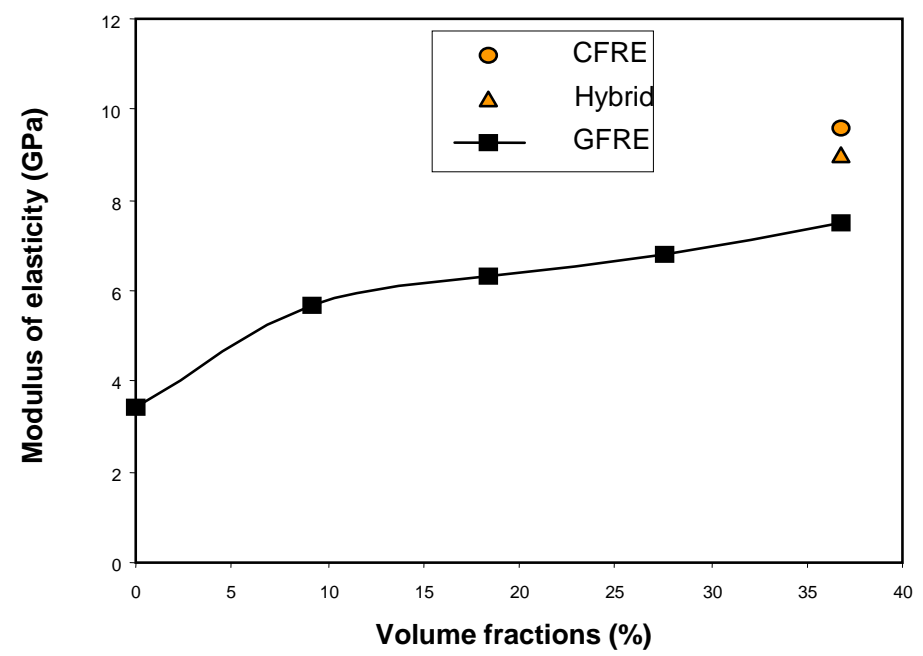

Fig. 4a: Longitudinal Modulus of Elasticity Versus Fiber Volume Fraction. 


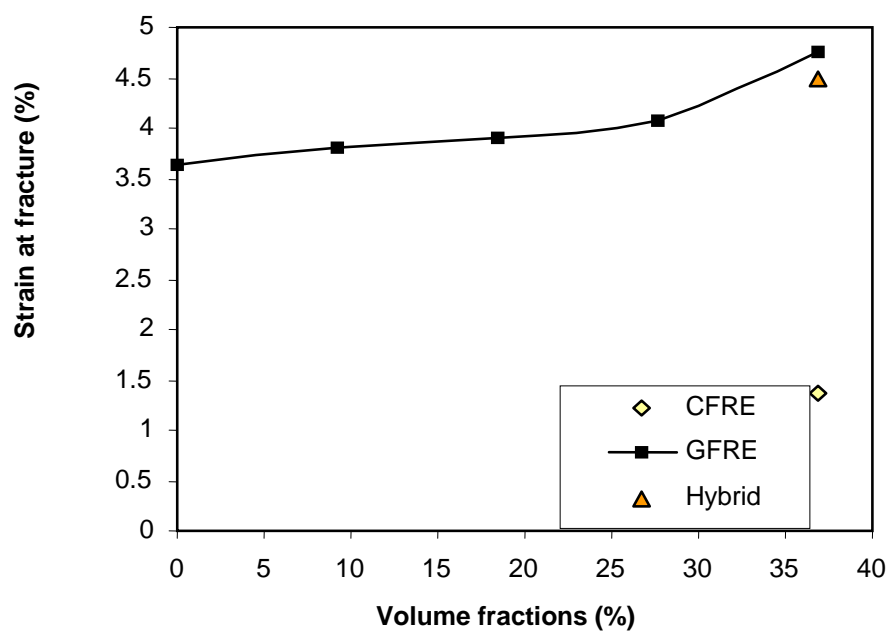

Fig. 4b: Fracture Strain Versus Volume Fractions of Fibers.

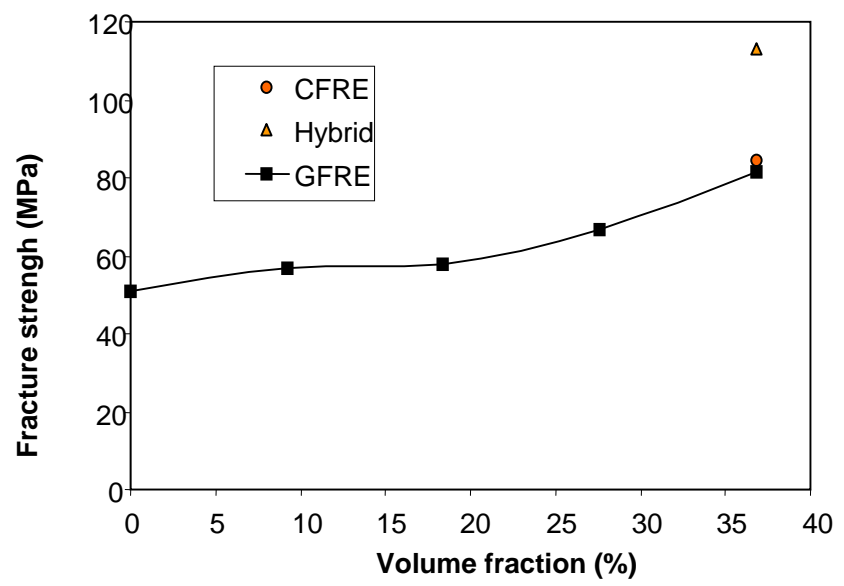

Fig. 4c: Fracture Stress Versus Volume Fraction of Fibers.

The modulus of elasticity of pure epoxy was found to be $3.45 \mathrm{Gpa}$, while that of epoxy-36.8 vol.\% GF was found to be $7.5 \mathrm{Gpa}$ (an improvement of 117\%). The moduli of epoxy-36.8 vol.\% CF and hybrid fibers were found to be $9.6 \mathrm{Gpa}$, and $9.0 \mathrm{Gpa}$, respectively. Thus, the improvements compared to pure epoxy are: $178 \%$, and $160 \%$, rspecitvely. Similar trends were observed for the compressive strength of the investigated composites.

As the carbon fibers were introduced, the magnitude of strain to fracture decreased for the different composites. This result could be explained in view of the fact that increasing carbon fibers volume fraction lead to a corresponding increase in the elastic modulus and stiffness, stiffness of the composite, see Table $\mathbf{4 b}$. Thus, the maximum strain to fracture decreased. The results of the present work are in good agreement with the results of similar studies $[15,16]$. 


\subsection{Fracture Behavior Under Compressive Loads}

Macroscopic observations of the fracture surfaces under compressive loads, Fig. 5a, b and $\mathbf{c}$ indicate that four different mechanisms can be seen. For pure epoxy, fracture is completely brittle associated with material fragmentation. For glass fiber reinforced epoxy, fiber debonding and pull-out played the main role in the fracture process. For carbon fiber reinforced epoxy, interlaminar shear fracture mechanism is observed with no or minimal fiber pull-out. Carbon/glass hybrid composites showed a mixed mode of interlaminar shear failure associated with transverse fiber pull out.

To examine these mechanisms thoroughly, SEM fractographs were employed. Figure 6a shows an SEM fractograph of epoxy-36.8 vol.\% GF. It is clear that fiber pull-out and fiber debonding played a major role in fracture as mentioned above. Figure $\mathbf{6 b}$ shows the fractograph of epoxy-36.8 vol.\% CF. It is clear that there is excellent bonding between fibers and matrix such that they behaved like a single phase material and fractured by interlaminar shearing. Minimal fiber pull out can be observed. Figure 6c shows the fracture of epoxy-36.8 vol.\% hybrid (CF/GF) reinforcement. The dominating mechanism is a mixed mode of fiber pull-out, fiber debonding, and matrix interlaminar shearing.

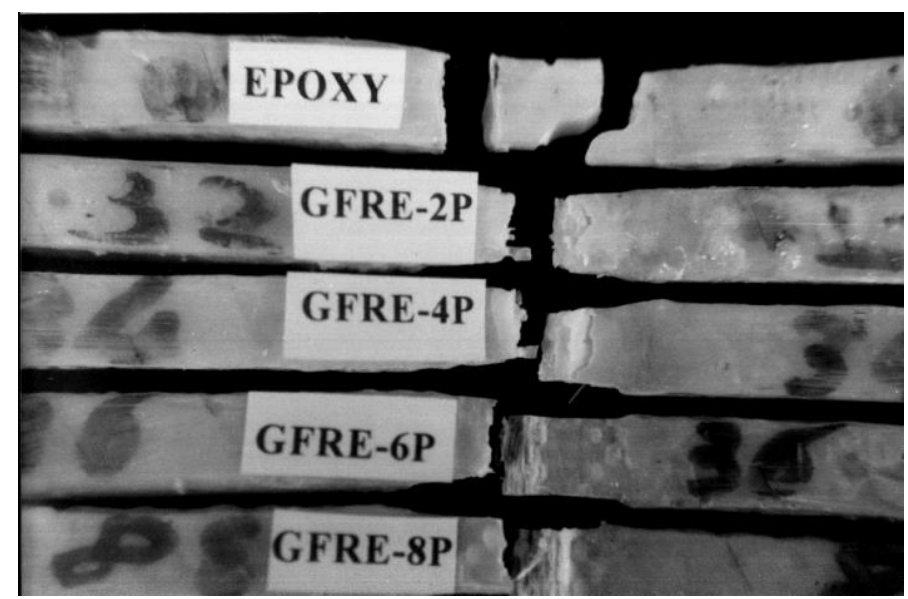

Fig. 5a: Macroscopic Fractograph of Pure Epoxy and GFRP.

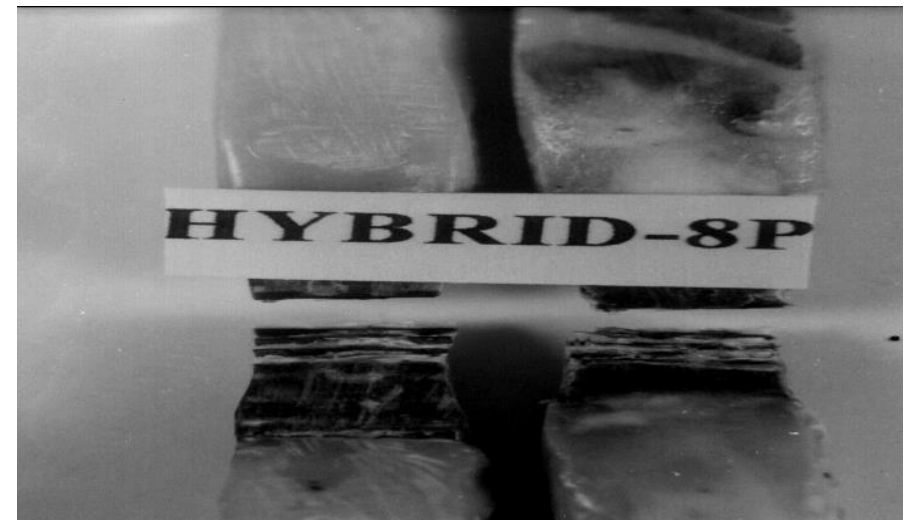

Fig. 5b: Macroscopic Fractograph of Hybrid Composites. 


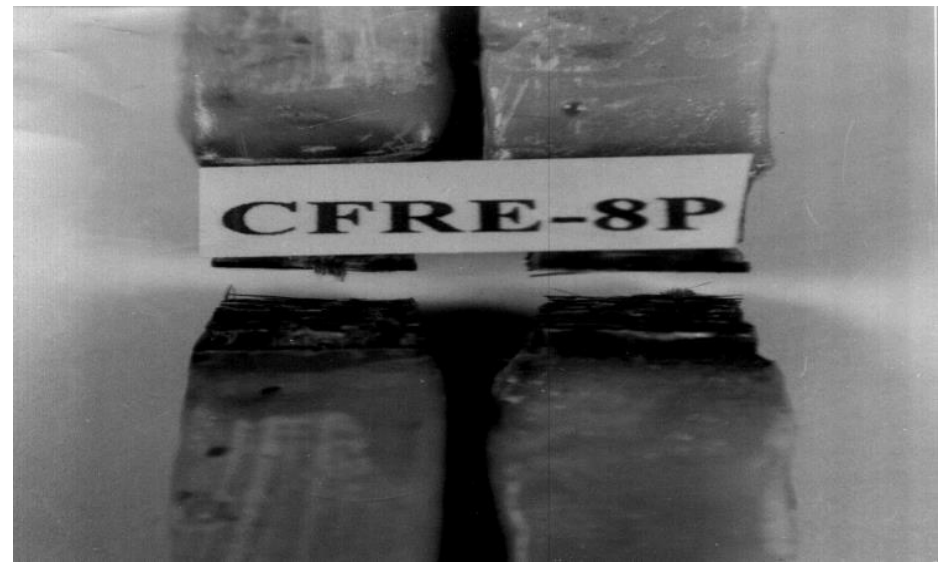

Fig. 5c: Macroscopic Fractograph of Carbon Fiber Composites.

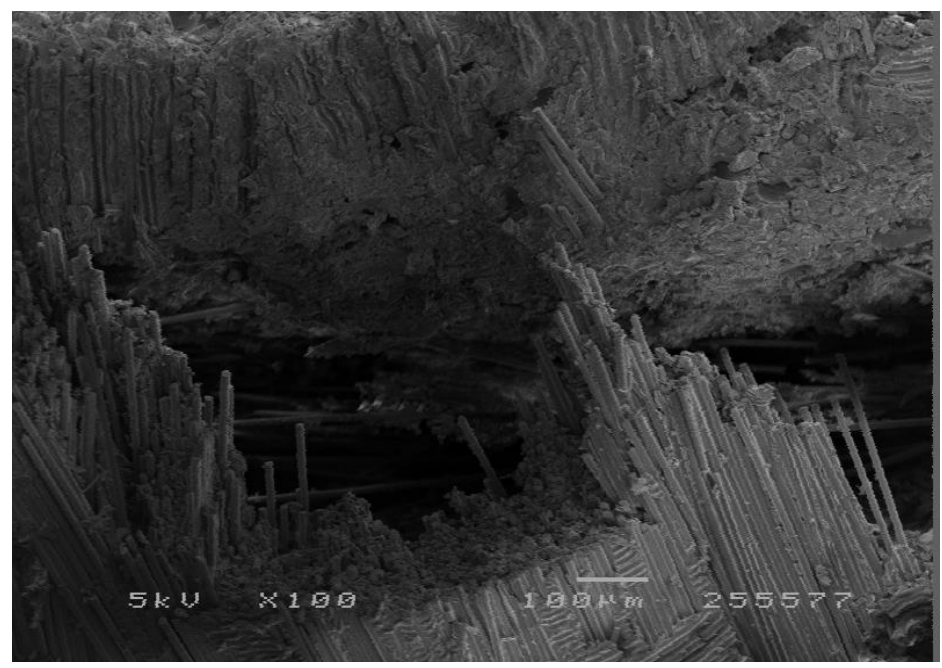

Fig. 6a: SEM Fractograph of Epoxy-36.8 vol.\% GF.

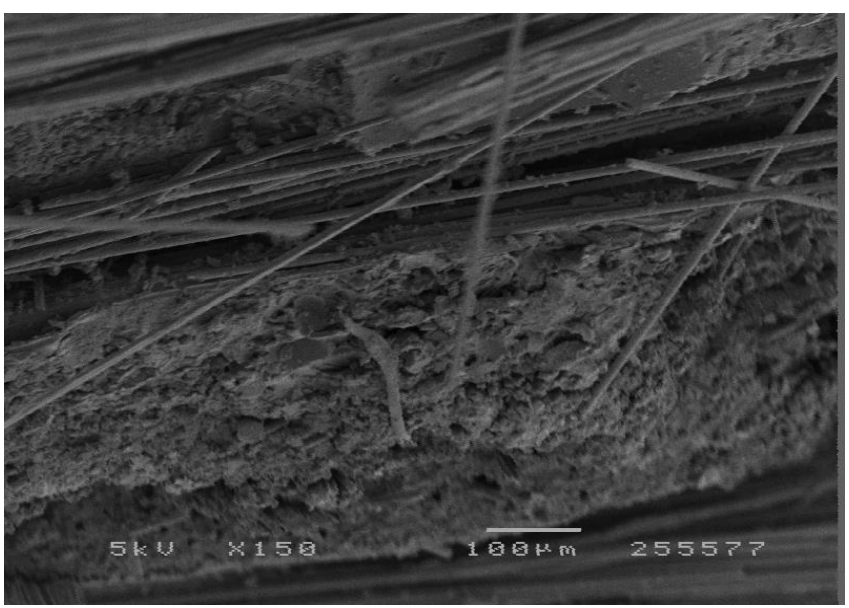

Fig. 6b: SEM Fractograph of Epoxy-36.8 vol.\% CF. 


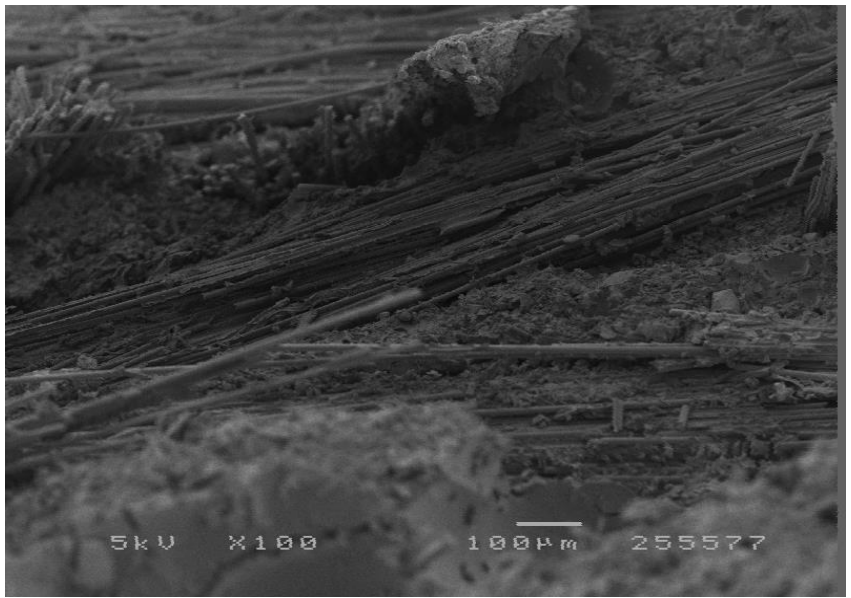

Fig. 6c: SEM Fractograph of Epoxy-36.8 vol.\% Hybrid Composites.

These fractographs indicate that the main factors controlling the fracture mechanism are the bond strength between fibers and matrix, and the type of fibers. Glass fibers were reported to have poor bond strength with epoxy [11], while carbon fibers were reported to have excellent bonding with epoxy. The present fractographs represent a strong support of these reported findings.

\subsection{Behavior Under Bending Loads}

Bending tests have the advantages of simple specimen preparation and testing. Endtapping, gripping, buckling, and slip are not issues for this test [17]. Under load, in 3 -point bending, the top side of the specimen is under compression, while the bottom surface is under tension. Theoretically, the neutral axis is in the mid plane, and is under zero bending stress, while the shear stress $\tau_{\mathrm{xy}}$, is maximum at the beam center.

Figure $7 \mathbf{a}, \mathbf{b}$, $\mathbf{c}$ shows examples of the load-deflection curves obtained from the testing machine. Three different curves were obtained during the present investigation. For pure (unreinforced) epoxy, completely linear elastic behavior is obtained. Specimens underwent a catastrophic, sudden fragmentation fracture at the maximum load after a linear elastic deflection. Fracture occurred at mid span section. Such behavior is typical of brittle materials, and was discussed in a paper by the present authors discussing tensile deformation behavior [13].

The second type of load-deflection curves was obtained for glass-fibers reinforced epoxy. Here, the specimens experienced a multistage fracture process. The loaddeflection curve, Fig. 7b, started by linear portion, followed by nonlinear behavior which ended by a load drop corresponding to the onset of first stage fracture. This stage is followed by a load constancy corresponding to continuing deflection under constant load. This stage ended by another load drop signifying the second stage fracture. This procedure is repeated until final fracture of the specimen. It was not possible-in the present study- to relate the number of failure stages to the number of reinforcement laminates. 
Epoxy reinforced by hybrid (glass/carbon) fibers showed a similar pattern of behavior. The third type of load-deflection curves was shown by carbon reinforced epoxy, Fig. 7c. Here, the load-deflection curves showed only one load drop at maximum load followed by defection under constant load till fracture.

For all types of composites, clear audible sounds were heard during the fracture process at the beginning of each fracture stage. These sounds represent load energy release associated with the fracture process.

Fracture started on the tension side and proceeded inwards towards the compression side. Fracture begins when the longitudinal fibers-perpendicular to load direction-crack or break[15].

Since the crosshead speed of the machine was kept constant during the test, the deflection of the specimen from the first load drop till the final separation of the specimen, could be taken to represent the time duration of crack growth [19].

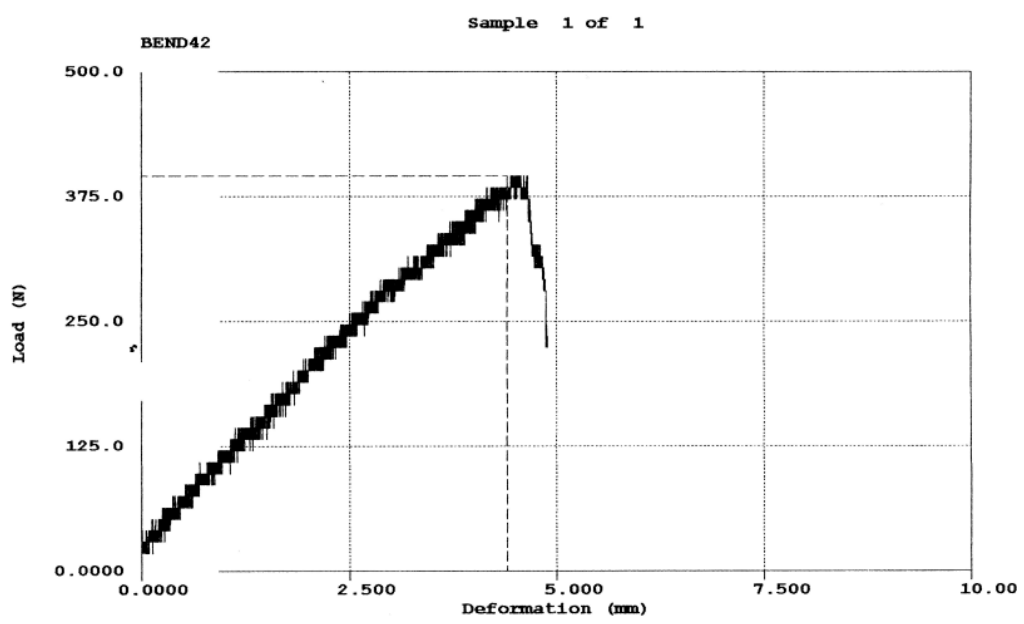

Fig. 7a: Bending Load-Deflection Curve for Pure Epoxy.

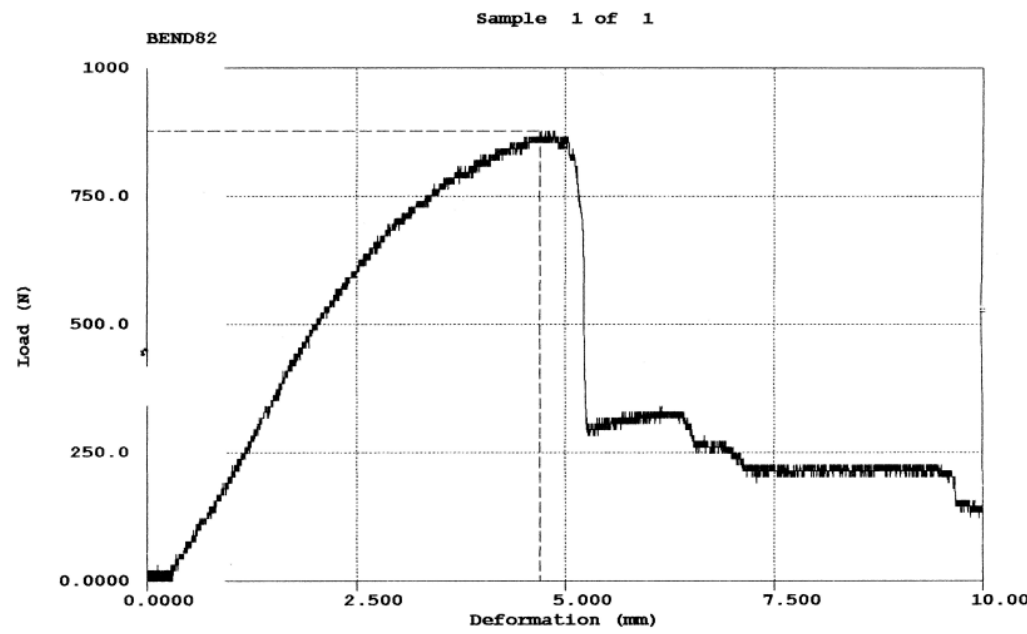

Fig. 7b: Bending Load-Deflection Curve for Glass Fiber composites. 


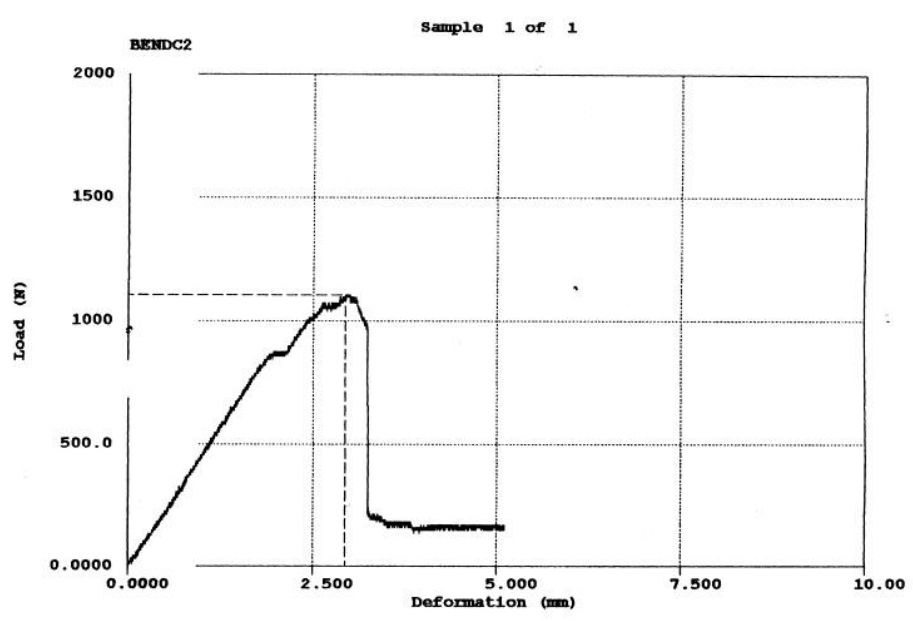

Fig. 7c: Bending Load-Deflection Curve for Carbon Fiber Composites.

Figures $\mathbf{8}$ and $\mathbf{9}$ show the variation of the flexure strength and the flexure modulus of different composites tested as a function of glass fiber volume fraction, and also as a function of the type of reinforcement. Although the flexure strength is not a standard material property, it is an important strength characteristic. It is considered as the bending counterpart of the ultimate tensile strength in uniaxial loading [12]. Tables 5a, $\mathbf{b}$ summarize the bending properties determined during the present study. It is clear that introducing woven glass fibers into the epoxy matrix lead to significant improvement of the flexure strength. At a $9.2 \mathrm{vol} . \% \mathrm{GF}$, the flexure strength improved by $27 \%$, while at $18.4 \mathrm{vol} . \% \mathrm{GF}$, the improvement reached $124 \%$, which at $36.8 \mathrm{vol} . \%$ GF reached a drastic improvement of $348 \%$. The effect of type of fibers on the flexure strength can be seen by comparing the flexure strength of the different types of fibers at the same volume fraction of $36.8 \%$ as shown in table $5 \mathrm{~b}$. It can be seen that the carbon fiber composite achieved an improvement of $34 \%$ over the glass fiber composites for the same volume fraction. The hybrid (GF/CF) composite showed a middle value of improvement of $14 \%$ compared to the GF composite (i.e., an improvement of $410 \%$ over pure epoxy).

The flexure modulus $\mathrm{E}_{\mathrm{b}}$, followed a similar trend, as shown in Tables $\mathbf{5 a}$, $\mathbf{b}$. The effective reinforcement of carbon fibers compared to glass fibers is due to two factors: the difference in strength between the two types of fibers, and due to the better bond strength of carbon with epoxy compared to glass fibers.

Table 6 shows the tensile deformation properties of the investigated composite materials determined in an earlier investigation [13].

Tables $\mathbf{5} \mathbf{a}$ and $\mathbf{b}$ show the bending properties for the same materials. Loading in bending and in tension have one common point, i.e. fracture occurs under tensile stresses. Comparing the magnitudes of the fracture stress under bending to those under tension (table 6), it can be seem that the former is always greater than the latter for all material condition except for the case of 36.8 vol. \% carbon fibers. In this case, the 
fracture stresses are the same under both types of loading. Fracture is mostly related to the tensile component of stress. Under tensile loads, the whole cross-section of the specimen is stressed in tension. Thus fracture occurs at a low stress compared to bending where part of the load is consumed in compressive deformation and the other is applying tension. Thus fracture under bending is delayed to a higher stress magnitude.

For the 36.8 vol. \% carbon fibers, it was shown from the SEM micrographs that the bond between fibers and matrix is very strong. Thus, once fracture stress is reached, interlaminar shearing acts to cause complete separation. Thus, fracture stress under tensile loads is the same as that under bending loads.

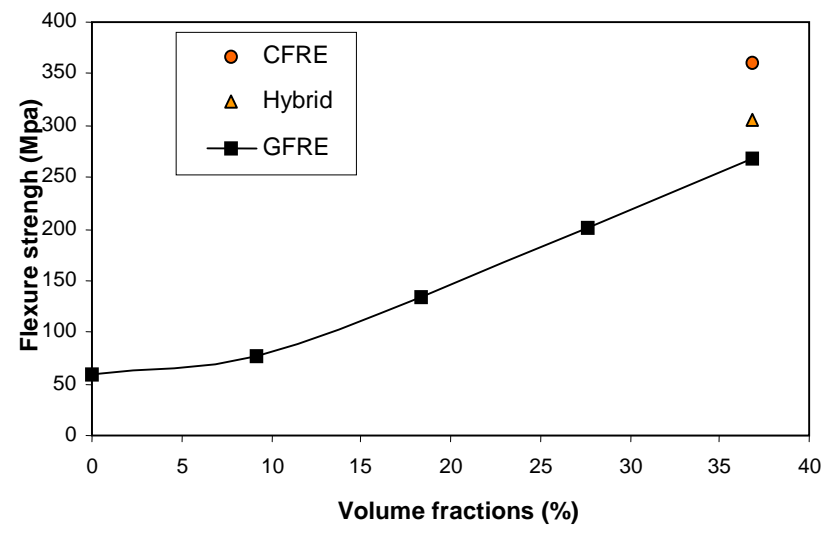

Fig. 8: Variation of Flexure Stress Versus Volume Fracture of the Different Composites.

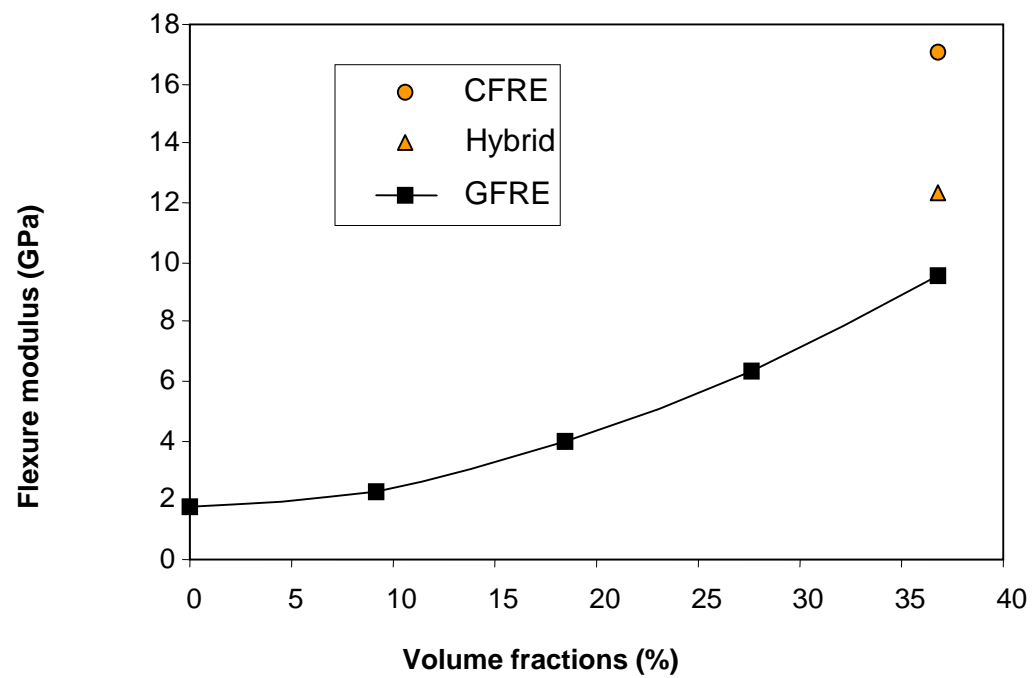

Fig. 9: Variation of Flexure Modulus Versus Volume Fracture of the Different Composites. 
Table 5a: Mean values of bending properties for GFRE .

\begin{tabular}{|c|c|c|}
\hline $\begin{array}{c}\text { Volume fractions of } \\
\text { FGRE }\end{array}$ & $\begin{array}{c}\text { Flexure strength, } \\
\text { (Mpa) }\end{array}$ & $\begin{array}{c}\text { Flexure modulus, } \\
\text { (Gpa) }\end{array}$ \\
\hline 0 & 59.66 & 1.8 \\
\hline $9.2 \%$ & 76.1 & 2.32 \\
\hline $18.4 \%$ & 133.9 & 4 \\
\hline $27.6 \%$ & 201.5 & 6.320 \\
\hline $36.8 \%$ & 267.4 & 9.55 \\
\hline
\end{tabular}

Table 5b: Mean values of bending properties for the different composites.

\begin{tabular}{|c|c|c|c|}
\hline $\begin{array}{c}\text { Types of } \\
\text { laminates }\end{array}$ & $\mathbf{V}_{\mathbf{f}}$ & $\begin{array}{c}\text { Flexure strength, } \\
\text { (Mpa) }\end{array}$ & $\begin{array}{c}\text { Flexure modulus, } \\
\text { (Gpa) }\end{array}$ \\
\hline GFRE & $36.8 \%$ & 267.4 & 9.55 \\
\hline Hybrid & $36.8 \%$ & 304.7 & 12.326 \\
\hline CFRE & $36.8 \%$ & 360 & 17.111 \\
\hline
\end{tabular}

Table 6: Tensile Deformation Properties Of Epoxy

Reinforced Composites [13].

\begin{tabular}{|c|c|c|c|}
\hline $\begin{array}{c}\text { Type \& Vol. } \\
\text { Fraction of Fibers }\end{array}$ & $\begin{array}{c}\text { Strain to } \\
\text { Fracture, } \boldsymbol{\varepsilon}_{\mathbf{f}}\end{array}$ & $\begin{array}{c}\text { Fracture } \\
\text { Strength, } \\
\sigma_{\mathrm{f}}, \mathbf{M p a}\end{array}$ & $\begin{array}{c}\text { Elastic } \\
\text { Modulus, } \\
\text { E, Gpa }\end{array}$ \\
\hline Glass 0 vol. \% & 1.475 & 46.29 & 2.66 \\
Glass 9.2 vol. \% & 1.45 & 42.65 & 5.67 \\
Glass 18.4 vol. \% & 1.52 & 74.7 & 7.8 \\
Glass 27.6 vol. \% & 1.88 & 108 & 9.6 \\
Glass 36.8 vol. \% & 2.65 & 173.4 & 10.6 \\
\hline Carbon 36.8 vol. \% & 2.53 & 360.63 & 16.8 \\
\hline Hybrid 36.8 vol. \% & 2.28 & 273.5 & 12.4 \\
\hline
\end{tabular}

Under axial compression and due to the fact that load transfer in composite materials is carried out by the matrix. And since epoxy is a brittle thermosetting plastic, thus its load carrying capacity is limited. Consequently, the compressive stresses are always lower than the tensile and bending fracture stresses, see tables $3 \mathrm{a}$ and $\mathrm{b}$.

\section{CONCLUSION}

An experimental study was conducted on epoxy reinforced with three different woven fibers, i.e., glass, carbon and hybrid (carbon/epoxy) fabrics. The effect of glass fiber volume fraction was investigated, and the different types of fibers were compared at a volume fraction of $36.8 \%$.

The mechanical behavior of the studied composites were determined under compressive, and 3-point bending loads. The following conclusions can be drawn: 
1. Addition of the investigated fibers to pure epoxy lead to significant improvements in all mechanical properties of the matrix.

2. The improvement in mechanical properties is proportionate to the glass volume fraction added to the matrix.

3. The mechanical properties of carbon reinforced epoxy is the highest followed by the hybrid reinforced epoxy, and then by the glass fibers one.

4. The reinforcement effect is affected by the strength of the fiber and by the bond strength between fibers and matrix.

5. Fiber pull-out and debonding are the main fracture mechanisms for glass fiber reinforced epoxy, while interlaminar shearing is the main mechanism for carbon fiber composites. Hybrid (C/G) composites showed a mixed mode mechanism.

6. The fracture process under bending was intermittent showing "knee" effect, and associated with audible sounds resulted from stress energy release. Fracture started on the tension side and proceeded inwards towards the compression side in stages related to the number of reinforcing laminates.

\section{REFERENCES}

[1] K. Loewenstein, The Manufacturing Technology of Continuous Glass Fibers, $2^{\text {nd }}$ ed., Elsevier, New York, 1983.

[2] B. Parkyn (ed.), Glass Reinforced Plastics, Butter Worth, London, 1970.

[3] C.J. Brinker, D.E. Clark and D.R. Ulrich (eds.), Better Ceramics Through Chemistry, North-Holland, New York, 1984.

[4] T. Davis, H. Palmour, and T. Porter (eds.), Emergent Process Methods for High Technology Ceramics, Plenum Press, New York, 1984.

[5] H.R. Clauser, Scientific American, V. 229, 36, July 1973.

[6] J.F. Schier and R.J. Juergens, Astronautics and Aeronautics, V. 44, Sept 1983.

[7] I.M. Daniel and O. Ishai, "Engineering Mechanics of Composite Materials", Oxford Univ. Press, Inc., 1994.

[8] H.H. Daken and A.A. Ismail, "Effect of Carbon on the Mechanical Behavior of Carbon/glass Woven Hybrid Composites", Sixth Aerospace and Technology (ASAT) Conference, Cairo, Egypt, 2-5 May, 1995, pp. 423-442.

[9] J.F. Nye, Physical Properties of Crystals, Oxford University Press, London, 1969, p. 131.

[10] Z. Hashin and B.W. Rosen, J. Appl. Mech., ASME, V. 31, 1964, p. 233.

[11] M.A. Hayat and S.M. Sulliman, "Mechanical and Structural Properties of Glass Reinforced Phenolic Laminates", Polymer Testing, V. 17, 1998, p. 79-97.

[12] Normunds Jekabsons and John Bystrom, "On the Effects of Stacked Fabric Layers on the Stiffness of a Woven Composite", Composites: Part B, V. 33, 2002, pp. 619-629.

[13] A.A.-Mazen, M.A. Abdel Ghafaar, and N.M. Mahallaway, "Tensile Deformation Behavior of Epoxy composites Reinforced with Three Different Woven Fabrics", Proceedings of the $11^{\text {th }}$ International Conference. On Composites Engineering, ICCE-11, 8 - 14 August 2004, South Carolina, USA.

[14] J. Bystrom, N. Jekabsons, and J. Varna, "An Evaluation of Different Models for Prediction of Elastic Properties of Woven Composites", Composites: Part B, V. 31, 2000, pp. 7-20. 
[15] Wang, Y. Baillargeon and T. Vu-Khanh, "Prediction of Fiber Orientation and Microstructure of Woven Fabric Composites After Forming", Composites Structures, V. 52, 2001, pp. 475-481.

[16] B. Yang, V. Kozey, S. Adanur, S. Kumar, "Bending, Compression, and Shear Behavior of Woven Glass Fiber-Epoxy composites", Composites: Part B, 31, 2000, pp. 715-721.

[17] Heru S.B. Rochardjo, J. Komotori, M. Shimizu, and Y. Miyano, J. Mat. Processing Techn., 67, 1997, pp. 89-93.

[18] Robert M. Jones, Mechanics of Composite Materials, $2^{\text {nd }}$ ed., Taylor and Francis, Pennsylvania, USA, 1999, p. 277.

[19] Yiping Qiu, Wei Xu, Youjiang, Mohamed Zikry, and Mansour H. Mohamed, "Fabrication and Characterization of Three Dimensional Cellular-Matrix Composites Reinforced with Woven Carbon Fabric", Composites Science and Technology, V. 61, 2001, pp. 2425-2435.

\section{سلوك المواد الإيبوكسية المركبة المقواة بالألياف المنسوجة تحت تأثثير أحمال ثني وضغط الأل}

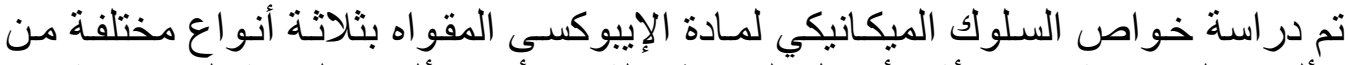

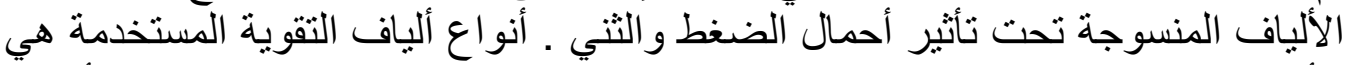

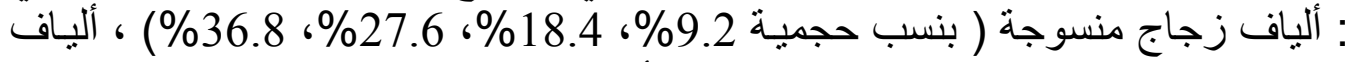
الكربون المنسوجة بنسبة حجمية 36.8\% ،

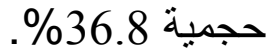

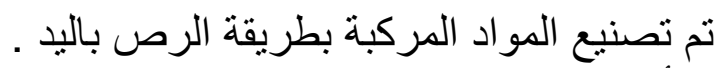

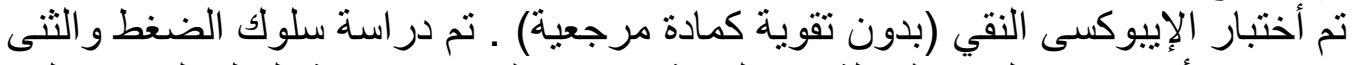

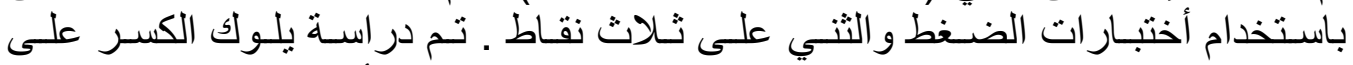
المستوى العياني والمستوى المجهري (باستخدام الميكرسكوب المان الألكترونى).

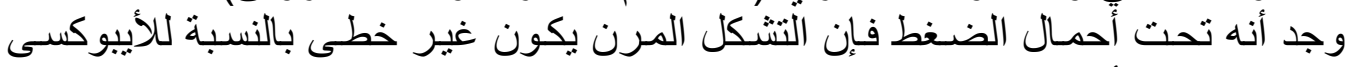

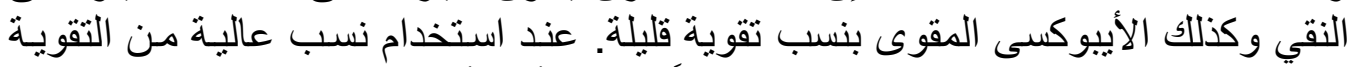

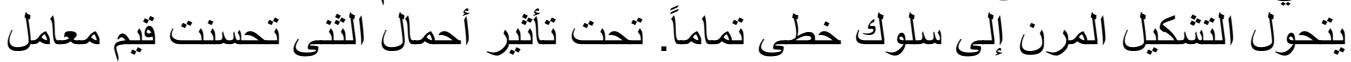

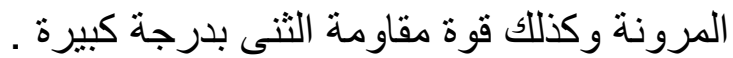

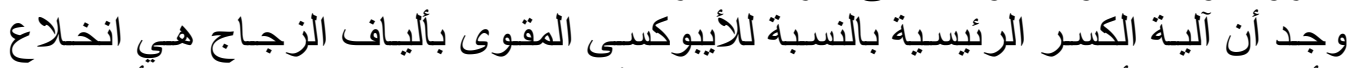

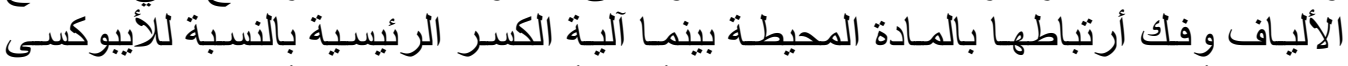

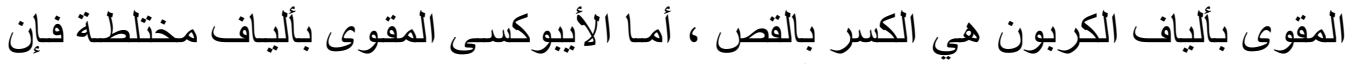
الكسر يكون بآلية مختلطة ما بين الآليتين المذكورتين. 